\title{
The role of landscape aesthetics in the total economic value of landscape: a case study of Albufera Natural Park
}

\author{
V. Estruch-Guitart ${ }^{1} \&$ M. Vallés-Planells ${ }^{2}$ \\ ${ }^{1}$ Department of Economy and Social Sciences, Group of International \\ Economics and Development, Universitat Politècnica de València, Spain \\ ${ }^{2}$ Department of Animal Science, Group of Aquaculture and Environment, \\ Universitat Politècnica de València, Spain
}

\begin{abstract}
Aesthetic enjoyment can be considered as part of the Total Economic Value (TEV) of landscape. The main purpose of this study is to estimate the relative importance of landscape aesthetics in the full value of Albufera Natural Park (Valencia, Spain). The Analytic Multicriteria Valuation Method (AMUVAM) is applied with the aid of a set of experts that include local and external stakeholders. AMUVAM is a combination of two established techniques: analytic hierarchy process (AHP) and discount cash flow (DCF). According to the experts, existence (EV) and bequest values (BV) are the most important in this landscape, followed by indirect use values (IUV). Aesthetic enjoyment (AE) represents 7\% of the TEV in Albufera Natural Park and $24 \%$ of the EV in Albufera Natural Park ( $€ 176$ million). Results reveal distinct patterns in the valuation of TEV and EV. In this way, together with the average, a range of values which shows the different sensitivities of society is provided.
\end{abstract}

Keywords: analytical hierarchy process, economic value, landscape valuation, multi-criteria decision making, wetland.

\section{Introduction}

Landscapes can be viewed as spatial human-ecological systems that perform a wide variety of functions that are, or can be, valued by humans for economic (productive), sociocultural, and ecological reasons (Termorshuizen and Opdam 
[1]). While most of these benefits are not captured in conventional market-based economic analysis (de Groot [2]), it is nevertheless important to have an assessment of the monetary values of the full set of goods and services provided by landscapes. This paper focuses on the valuation of landscape aesthetics, as a component of the Total Economic Value (TEV) of landscape.

With regard to the economic valuation of aesthetic quality, a field that began in the 1970s (Price [3]), the most frequently used methods are revealed preference and stated preference (Oueslati and Salanié [4]). Revealed preference techniques are based on people's actual behaviour in real markets, in relation to the consumption of particular goods (e.g. Kong et al. [5]). The focus of these methods is to estimate the economic value of landscapes at a certain moment, in order to provide information to policy makers to justify preservation or allocation of resources. The second category, stated preference methods, focuses on change involving both negative (e.g. Price [6]) and positive (e.g. Hynes et al. [7]) impacts on landscape. Such methods assume that there is no related market for landscapes, but that a hypothetical market can be constructed. Unlike revealed preference, stated preference methods include non-use values and are addressed to changes in valuations of landscapes, rather than to the valuation of landscape "per se" (Moran [8]).

Concerning the natural resources management point of view, not only is important to know the absolute value of a certain service (e.g. aesthetic enjoyment) but also to consider all the benefits provided by a certain landscape and their relative importance. While the first issue is tackled by the methods described above, the second is not. This knowledge can help decision makers in two ways: on the one hand, to define the objectives of public interventions and resource allocations; on the other hand, to inform and make people aware of the values of various benefits provided by a landscape.

In this way, the focus of this work is on the relative importance of landscape aesthetics in the full value of Albufera Natural Park (Valencia). For this purpose, a method different from the ones cited above is applied. This method has been used in the economic valuation of environmental assets such as Pego-Oliva Wetland (Aznar et al. [9]). Nevertheless, its application to the valuation of aesthetic enjoyment is new. The way AMUVAM tackles the problem of valuation differs from that of the most commonly used methods of landscape valuation. Economic value of non-market benefits under AMUVAM is obtained indirectly, by comparing the relative degrees of importance ascribed to different types of landscape values. Respondents are asked to state the importance of each of the components of the Total Economic Value (TEV) by comparing them by pairs, considering aesthetic enjoyment as part of the TEV.

\section{Methods}

Based on multi-criteria analytical techniques, AMUVAM enables to determine $\mathrm{TEV}$, the relative values of components of TEV and the relationship between values that lack an associated market (and hence a market price) and values that do have a market price. 
In AMUVAM, it is assumed that the known value of some of the components of TEV may be used to derive the values of the remaining components, such as the aesthetic value. Hence, it allows to assess (i) the relative importance and (ii) the monetary values of all the components of the TEV (direct (DUV), indirect (IUV), option/quasi-option (OV), existence (EV) and bequest values (BV)) and the disaggregated values within these components.

Two techniques are involved in AMUVAM: the analytic hierarchy process (AHP) and discount cash flow analysis (DCF). AHP, the method developed by Saaty [10] which has been broadly used in different fields (e.g. Chow and Sadler [11]), is implemented to obtain the relative weights of the TEV components, while DCF (IVSC [12]) is used to determine the economic values of the services associated with direct use (DUV).

The aesthetic value of a landscape may be considered one of the values that comprise its TEV. Although this aspect of a landscape's value may be conceived as a use value rather than a non-use value (Swanwick et al. [23]), in this work, following previous authors (e.g. Costanza et al. [13]; de Groot et al. [14]), aesthetic enjoyment is viewed as an existence value.

\subsection{Site description}

The current work was developed in the Albufera de Valencia wetland. This wetlands area, of 21,000 hectares, located in eastern Spain, $10 \mathrm{~km}$ from the city of Valencia, has been included in the RAMSAR Convention since 1990 and in the SPAs since 1991 and is protected under the designation of Natural Park. Moreover, due to its natural, cultural and aesthetic value, it has become a source of identity for the population of Valencia (Sanchis [15]).

Three main ecosystems compose Albufera de Valencia: the lake, the marshland and the sandbar. The name Albufera originates from the Arab term al-Buhayra (small sea), which references the lake that is the central element of this landscape. This lake originated from an ancient gulf that became enclosed as a result of sediments that were deposited into it from two rivers (Turia and Jucar River), forming a sandbar that separated the lake from the sea. The extent of the lake has changed over time, due to the development of agriculture, especially rice, which was introduced into the area in the 18th century. Today, the surface of the lake is approximately 2,800 hectares.

\subsection{Definition of the TEV components}

According to Barbier [16], the value of a wetland is derived from its assets, flows and attributes. Assets, also called products, goods or stocks, are those components which are directly exploitable by humans and provide an economic benefit. Flows or services refer to the ways in which ecosystem processes contribute to human well-being. They usually refer to environmental regulating services (flood control, erosion prevention ...), but also to recreational and cultural benefits derived from nature. Hence they involve material and immaterial benefits for humans. Nowadays, both goods and services are included under the umbrella of ecosystem services (MEA [17]). With regard, to the third concept, attribute, it refers to those 
components of a wetland that have value because they induce certain economic uses or they have value in themselves (e-g. biodiversity, cultural heritage). Taking into account these components of a wetland value, Barbier [16] proposed the concept of TEV, which distinguishes between use and non-use values. The TEV components and their associated goods, services and attributes for the case study of Albufera Natural Park (Table 1) were based on previous work on economic valuation of wetlands, on the study area and on the discussion with experts (Gómez-Limón and Arriaza [18]) that would also take part in the weight assignment stage (Section 2.3).

Table 1: Components of Total Economic Value in Albufera of Valencia. DUV: direct use values; IUV: indirect use values; OV: option, quasi-option values; BV: bequest values; EV: existence values.

\section{VALUES ACTIVITIES AND/OR FUNCTIONS}

DUV Rice, hunting, fishing

IUV Support of other ecosystems, flood control, coastal stabilisation, groundwater recharge, retention of nutrients, recreation

OV Possible future uses (direct and indirect); value of information in the future

EV Biodiversity; cultural heritage; aesthetic enjoyment

BV Bequest value

\subsection{Weight assignment of TEV components by experts}

In this step, AHP (Saaty [10]) is implemented in order to obtain the relative weights of TEV components and EV components from a group of experts. They must have a deep knowledge of the area and represent the different points of view on the wetland.

Experts weight components at two levels (Figure 1). They start weighing TEV components (level 1) and then, they weigh EV components (level 2). The survey starts with a brief explanation of the goal of the work and the meaning of the different types of values. Then, experts are asked to compare TEV and EV components by pairs. This comparison is implemented in two steps. First, they decide which of the two components the most important is. The question posed to the participants is the following: of the two values being compared, which is considered more important by society with respect to the overall value of Albufera Natural Park? Second, they express the intensity of importance, using the scale of comparisons shown in Table 2. According to how close are the elements compared in importance, one can use the different values of the fundamental scale. 


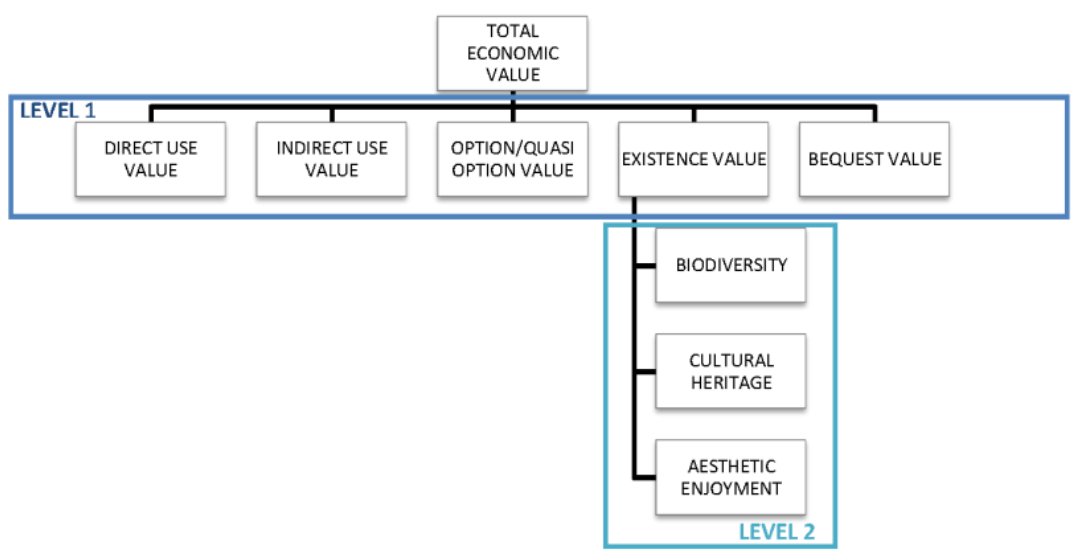

Figure 1: Diagram showing TEV and EV components compared in the survey.

Table 2: The fundamental scale for pairwise comparisons. Source: Saaty [10].

\begin{tabular}{|c|c|c|}
\hline $\begin{array}{l}\text { NUMERIC } \\
\text { SCALE }\end{array}$ & DEFINITION & EXPLANATION \\
\hline 1 & $\begin{array}{c}\text { Equal } \\
\text { importance }\end{array}$ & $\begin{array}{l}\text { Two elements contribute equally to } \\
\text { the property or criterion }\end{array}$ \\
\hline 3 & $\begin{array}{l}\text { Moderate } \\
\text { importance }\end{array}$ & $\begin{array}{l}\text { Experience and judgment slightly } \\
\text { favour one element over another }\end{array}$ \\
\hline 5 & $\begin{array}{l}\text { Strong } \\
\text { importance }\end{array}$ & $\begin{array}{l}\text { Experience and judgment strongly } \\
\text { favour one element over another }\end{array}$ \\
\hline 7 & $\begin{array}{l}\text { Very strong } \\
\text { importance }\end{array}$ & $\begin{array}{l}\text { Experience and judgment very } \\
\text { strongly favour one element over } \\
\text { another; its dominance is } \\
\text { demonstrated in practice }\end{array}$ \\
\hline 9 & $\begin{array}{l}\text { Extreme } \\
\text { importance }\end{array}$ & $\begin{array}{l}\text { The evidence favouring one activity } \\
\text { over another is of the highest possible } \\
\text { order of affirmation }\end{array}$ \\
\hline
\end{tabular}

Their answers are used to obtain the comparison matrices. There are as many matrices as consulted stakeholders. The consistency ratios (CR) are then verified, and eigenvalues are calculated. Finally, the geometric mean of the eigenvalues is calculated (Saaty [10]) to obtain the weights of the various TEV and EV components.

For this study, the set of experts included local and external stakeholders representing the key topics of the area, in terms of exploitation and conservation of natural resources. Experts were representatives of: Albufera Technical Office, in charge of the Natural Park management, Valencia Regional Agricultural department, Valencia Regional Environmental departments related to natural environment and landscape sections, farmer trade associations, irrigation 
community, fishing community, rice cooperatives, ecologist associations and university lecturers specialised in landscape planning, botanic and phitotecnics.

In this study, TEV weights were derived from the responses of 43 experts conducted during two surveys, a previous one in 2005 (25 experts) and another in 2012 (18 experts). EV weights were obtained from the 18 experts consulted in 2012. The incorporation of the data obtained in a previous study in 2005 allowed the comparison the values of TEV components.

\subsection{Calculation of the pivot value}

This stage aims to obtain the economic value, called the pivot, of a TEV component. The DUV is usually the pivot because it associates economic functions with market values. The pivot value is based on both present and future revenues derived from the exploitation of these resources. DCF is a method of valuation based on the revenues an asset generates over a period of time (IVSC [12]).

This method assumes that the economic value of an asset corresponds to the present value of the sum of the future revenues derived from this asset. In this way, the present value of future expected net cash flows is calculated using a discount rate which converts a future monetary sum into present value. In this case, the pivot value is derived from rice, hunting and fishing activities. First, the annual revenues derived from the incomes and expenditures of these three activities are calculated. Then, following Evans [19], this cash flow is updated applying a 3\% $\operatorname{tax}$ (Eq. 1).

$$
\text { DUV value }=\frac{\text { Cash flow of the services provided by DUV }}{\text { Discount rate }}
$$

\subsection{Calculation of the TEV and its related components}

The hypothesis behind the TEV as the sum of its partial components is implicit in this stage. Since the TEV is not considered a market value, but an indicator of the value of an environmental asset, the sum of its partial values may be seen as an estimate of its real value (Adamowicz et al. [20]; Hanley et al. [21]; Colombo et al. [22]).

Once the pivot is known, the values of the other TEV components (IUV, OV, $\mathrm{EV}, \mathrm{BV}$ ) are estimated, using the eigenvalue determined through the AHP method, so that the relative weights of the TEV components are defined (Eqs (2)-(5)). The TEV of the environmental asset is then determined by adding up all the partial values (Eq. (6)). The value thus obtained indicates the total economic value of the Albufera landscape. Then, the value of each EV component (biodiversity, cultural heritage and aesthetic enjoyment) is derived from their weights and the known economic value of the EV (Eqs (7)-(9)).

$$
\begin{aligned}
& I V \text { value }=\frac{D U V \text { value }}{D U V \text { weight }} \times I V \text { weight } \\
& \frac{O}{O V} \text { value }=\frac{D U V \text { value }}{D U V \text { weight }} \times \frac{O}{O V} \text { weight }
\end{aligned}
$$




$$
\begin{aligned}
E V \text { value } & =\frac{D U V \text { value }}{D U \text { weight }} \times E V \text { weight } \\
B V \text { value } & =\frac{D U \text { value }}{D U V \text { weight }} \times B V \text { weight } \\
D U V \text { value }+I U V \text { value } & +O / O V \text { value }+E V \text { value }+B V \text { value } \\
B \text { value } & =E V \text { value } \times B \text { weight } \\
C H \text { value } & =E V \text { value } \times C H \text { weight } \\
A E \text { value } & =E V \text { value } \times A E \text { weight }
\end{aligned}
$$

\subsection{Analysis of expert valuations}

Once average values are obtained for the TEV and EV components, this stage focuses on the analysis of the differences among the weights assigned to these components by the experts. For this purpose, first a cluster analysis is implemented and, then, a variance analysis is applied in order to check if there are significant statistical differences among the groups.

Cluster analysis produces hierarchical groups of items based on distance measures of dissimilarity or similarity. The variables used are, firstly, the components of TEV and, secondly, the components of EV. Euclidean distance is used to calculate the distance between two items and the clustering method is the method of average linkage between groups (SSPS Inc.).

Significant statistical differences among the groups derived from cluster analysis of TEV components are estimated through t-test. It compares sample means by calculating Student's t and displays the two-tailed probability. TEV components are considered the dependent variables whereas the variable obtained from cluster analysis is the independent variable. Variance analysis (ANOVA) is applied for EV components. In particular one-way analysis is implemented which produces a one-way analysis of variance for an interval-level dependent variable by one numeric independent variable that defines the groups for the analysis. EV components are assumed the dependent variables and the variable derived from cluster analysis is the independent variable. Post hoc analysis which tests for comparisons of all possible pairs of group means or multiple comparisons is Bonferroni $t$ test. This test is based on Student's t statistic and adjusts the observed significance level for the fact that multiple comparisons are made.

\section{Results}

\subsection{Calculation of the TEV components}

The survey was carried out in August, September and October of 2005 and in October 2012 with completion time for the survey averaging 25 minutes. The pairwise comparisons made by the experts were used to calculate the eigenvalues, which indicated the relative importance, from the experts' points of view, of each 
TEV component. 34 consistent matrices, whose CRs did not exceed 10\%, were used to calculate the aggregated eigenvalue, which was estimated by calculating the geometric mean of the eigenvalues and was normalised by addition (Table 3 ).

Table 3: Aggregated and normalised eigenvalues.

\begin{tabular}{cccc}
\hline TEV & \multicolumn{3}{c}{ WEIGHTS OF TEV COMPONENTS } \\
\hline & Cluster 1 & Cluster 2 & Global \\
UDV & 0.0636 & 0.3285 & 0.1375 \\
UIV & 0.1216 & 0.2620 & 0.1882 \\
OV & 0.0489 & 0.1307 & 0.0822 \\
EV & 0.4358 & 0.1107 & 0.2979 \\
BV & 0.3300 & 0.1681 & 0.2942 \\
\hline
\end{tabular}

Table 4 shows incomes and expenditures associated with these activities. After updating the calculated cash flow to account for a 3\% tax (Evans [19]), the estimated DUV in Albufera was $€ 333$ million. With regard to the TEV, Table 5 shows the global value and the values corresponding to the two groups derived from cluster analysis.

Table 4: Incomes and expenditures $(€)$ related to direct use values.

\begin{tabular}{cccc}
\hline & INCOMES & EXPENDITURES & CASH FLOW \\
\hline Rice & $49,645,706$ & $40,001,538$ & $9,644,168$ \\
Hunting & 598,564 & 390,902 & 207,662 \\
Fishing & 306,595 & 154,920 & 151,675 \\
Total & $50,550,865$ & $40,547,360$ & $10,003,505$ \\
\hline
\end{tabular}

Table 5: Albufera economic value according to the aggregated weights assigned by experts.

\begin{tabular}{ccccccc}
\hline TEV & \multicolumn{3}{c}{ VALUE IN 1,000€ } & \multicolumn{2}{c}{ VALUE FLOW IN 1,000/YEAR } \\
\hline & Cluster 1 & Cluster 2 & Global & Cluster 1 & Cluster 2 & Global \\
UDV & 333,450 & 333,450 & 333,450 & 10,003 & 10,003 & 10,003 \\
UIV & 637,931 & 266,014 & 456,593 & 19,138 & 7,980 & 13,698 \\
OV & 256,673 & 132,632 & 199,410 & 7,700 & 3,979 & 5,982 \\
EV & $2,285,896$ & 112,423 & 722,540 & 68,577 & 3,373 & 21,676 \\
BV & $1,730,864$ & 170,609 & 713,700 & 51,926 & 5,118 & 21,411 \\
& $5,244,814$ & $1,015,127$ & $2,425,694$ & 157,344 & 30,454 & 72,771 \\
\hline
\end{tabular}




\subsection{Calculation of the EV components}

Founding on the geometric mean of the 15 consistent matrices and the EV estimated in the preceding section, the economic values of the EV components (biodiversity (B), cultural heritage $(\mathrm{CH})$ and aesthetic enjoyment $(\mathrm{AE})$ ) were calculated. Table 6 shows the relative importance of these three components and Table 7 shows their economic value for the whole group and for the three groups derived from cluster analysis. The assessed value of aesthetic enjoyment in Albufera Natural Park is $€ 146$ million ranging between $€ 86$ and $€ 186$ million.

Table 6: Weights of EV components. B: biodiversity; $\mathrm{CH}$ : cultural heritage; AE: aesthetic enjoyment.

\begin{tabular}{ccccc}
\hline EV & \multicolumn{3}{c}{ WEIGHTS OF EV COMPONENTS } \\
\hline & Cluster 1 & Cluster 2 & Cluster 3 & Global \\
B & 0.6229 & 0.7741 & 0.1047 & 0.5529 \\
CH & 0.1272 & 0.1130 & 0.6370 & 0.2035 \\
AE & 0.2499 & 0.1130 & 0.2583 & 0.2436 \\
\hline
\end{tabular}

Table 7: Existence value according to the aggregated weights assigned by experts.

\begin{tabular}{|c|c|c|c|c|c|c|c|c|}
\hline & \multicolumn{4}{|c|}{ VALUE IN $1,000 €$} & \multicolumn{4}{|c|}{ VALUE FLOW IN $1,000 € /$ YEAR } \\
\hline \multirow[t]{2}{*}{$\overline{E V}$} & \multicolumn{4}{|c|}{722,540} & \multicolumn{4}{|c|}{21,676} \\
\hline & Cluster 1 & Cluster 2 & Cluster 3 & Global & Cluster 1 & Cluster 2 & Cluster 3 & Global \\
\hline B & 450,070 & 559,304 & 75,650 & 399,487 & 13,502 & 16,779 & 2,269 & 11,985 \\
\hline $\mathrm{CH}$ & 91,922 & 81,618 & 460,258 & 147,068 & 2,758 & 2,449 & 13,808 & 4,412 \\
\hline $\mathrm{AE}$ & 180,548 & 81,618 & 186,632 & 175,985 & 5,416 & 2,449 & 5,599 & 5,280 \\
\hline
\end{tabular}

\section{Discussion}

This work has shown how AMUVAM method can provide knowledge about the importance of the aesthetic value of landscape in comparison with the other components of the TEV. According to the results, the aesthetic value of landscape corresponds to $7 \%$ of the TEV and $24 \%$ of the EV in Albufera Natural Park (€176 million).

However, the statistical analysis of expert weights also reveals the existence of distinct patterns in the valuation of TEV and EV components. These differences in weight assignment may be attributed to the existence of different interests and attitudes towards the valued asset. This finding is in agreement with previous authors working in the field of land management who have reported differences in 
weight assignment among different expert groups (Chow and Sadler [11]). In this way, this study provides, together with the average value, a range of values that reflect the different sensitivities of society for the TEV and its components.

Regarding the TEV, cluster analysis suggests two different patterns environmentalist and utilitarian - which show significant statistical differences for all the components of the TEV (Table 5). The utilitarian group (cluster 1) gives a higher importance to use values which represent $72 \%$ of the TEV. While non-use values correspond to $77 \%$ of the TEV according to the environmentalist group (cluster 2). According to this analysis, the TEV of Albufera Natural Park ranges between $€ 1,015$ and $€ 5,244$ billion.

With regard to EV, three different groups have been identified (Table 7). The first and the second cluster are similar in terms of the importance assigned to biodiversity and cultural heritage. But they differ on the value of aesthetic enjoyment. The weight of aesthetic enjoyment in the first cluster $(25 \%)$ is twice as high as in the second cluster (11\%). Whereas the third cluster is similar to the first one in terms of the weight of aesthetic enjoyment $(26 \%)$, but it is very different to the other two groups in biodiversity and cultural heritage values. Hence, results suggest that the weight assigned to aesthetic enjoyment ranges between $11 \%$ and $26 \%$ of the EV, which corresponds to $3.56 \%$ and $7.61 \%$ of the TEV.

Despite the lack of consensus in the importance of the different components of the TEV, it is noted that all the TEV components receive similar weights in both surveys (2005 and 2012) except for the BV. Unfortunately, this comparison could not be conducted for the aesthetic value, since no data about the EV components was collected in 2005 .

\section{Conclusions}

AMUVAM methodology has been applied to determine the importance of aesthetic enjoyment in the full value of Albufera Natural Park. According to this work, the average value of aesthetic enjoyment in Albufera Natural Park corresponds to $€ 176$ million and its range is between $€ 82$ and $€ 187$ million. This range of values corresponds to the different patterns of valuation identified in this study which reflect the diversity of sensitivities within society with regard to the components of TEV.

The results obtained from AMUVAM may be useful in more objectively prioritising future environmental initiatives by enabling to select those initiatives with greatest impact on the aspects most valued by society. It may also contribute to a better allocation of investments and subsidies, to better align the objectives of such expenditures with the importance attached to those objectives by society.

\section{References}

[1] Termorshuizen JW, Opdam P, Landscape services as a bridge between landscape ecology and sustainable development. Landscape Ecol. 24: pp. 1037-1052, 2009. 
[2] de Groot R, Function-analysis and valuation as a tool to assess land use conflicts in planning for sustainable, multi-functional landscapes. Landscape Urban Plan. 75(3-4): pp. 175-186, 2006.

[3] Price C, Landscape economics. MacMillan Press, London. p. 168, 1978

[4] Oueslati W, Salanié J, Landscape valuation and planning. J. Environ. Plan. Manage. 54 (1): pp. 1-6, 2011.

[5] Kong F, Yin H, Nakagoshi N, Using GIS and landscape metrics in the hedonic price modeling of the amenity value of urban green space: A case study in Jinan City, China. Landscape Urban Plan. 79: pp. 240-252, 2007.

[6] Price C. Landscape economics at dawn: An eye-witness account. Landscape Res. 33(3): pp. 263-280, 2008.

[7] Hynes S, Campbell D, Howley P, A holistic vs. an attribute-based approach to agri-environmental policy valuation: Do welfare estimates differ? J. Agr. Econ. 62 (2): pp. 305-329, 2011.

[8] Moran D, The economic valuation of rural landscapes. SEERAD, Edinburg. Research Study AA211. Available in http://www.snh.org.uk/pdfs/strategy/ landscapes/Annex.pdf (1 December 2014), 2005.

[9] Aznar J, Estruch V, Vallés M, Valuation of environmental assets by the multicriteria AMUVAM method and its application to the Pego-Oliva wetland. Environ.Eng. Manag. J. 13(3): pp. 1535-1547, 2014.

[10] Saaty T, The analytic hierarchy process: planning, priority setting, resource allocation. RWS Publications, Pittsburgh. p. 287, 1980.

[11] Chow TE, Sadler R, The consensus of local stakeholders and outside experts in suitability modeling for future camp development. Landscape Urban Plan. 94: pp. 9-19, 2010.

[12] IVSC, International valuation standards 2001. International Valuation Standards Committee, London, 2001.

[13] Costanza R, d'Arge R, de Groot R, Farber S, Grasso M, Hannon B, Limburg K, Naeem S, O’Neill RV, Paruelo J, Raskin RG., Sutton P, Van Den Belt $\mathrm{M}$, The value of the world's ecosystem services and natural capital. Nature 387: pp. 253-260, 1997.

[14] de Groot, R., Wilson, M.A., Boumans, R.M.J., A typology for the classification, description and valuation of ecosystem functions, goods and services. Ecol. Econ. 41(3), 2002.

[15] Sanchis C, The construction of a landscape icon. The Albufera of Valencia (1889-1939) (La construcció d'una icona paisatgística. L'Albufera de València (1889-1939)). SAITABI 57: pp. 241-260 (in Catalan), 2007.

[16] Barbier EB, Valuing Environmental Functions: Tropical Wetlands. Land Econ. 70(2): pp. 133-173, 1994.

[17] MEA, Ecosystems and human well-being. Synthesis. Island Press. Washington, DC. Millennium Ecosystem Assessment, 2005.

[18] Gomez-Limón JA, Arriaza M, What does society demands from rural areas? Evidence from Southern Spain. New Medit N. 1: pp. 2-12, 2013.

[19] Evans DJ, Social discount rates for the European Union. Fifth Milan European Economy Workshops, Milan, 2006. 
[20] Adamowicz W, Boxall P, Williams M, Louviere J, Stated preference approaches for measuring passive use values: Choice experiments and contingent valuation, American Journal of Agricultural Economics 80(2): pp. 65-75, 1998.

[21] Hanley N, Wright R, Adamowicz V, Using choice experiments to value the environment: design issues, current experience and future prospects. Environ. Resour. Econ., 11(3-4): pp. 413-428, 1998.

[22] Colombo S, Calatrava-Requena J, Hanley N, Analysing the social benefits of soil conservation measures using stated preference methods. Ecol. Econ. 58(4): pp. 850-861, 2006.

[23] Swanwick C, Hanley N, Termansen M, Scoping study on Agricultural Landscape Evaluation. Final Report to DEFRA, University of Leeds, The University Of Sheffield \& University of Stirling, 2007. Available in http://webarchive.nationalarchives.gov.uk/20130402151656/http:// archive.defra.gov.uk/evidence/economics/foodfarm/reports/agrlandval/ Mainrep.pdf 